\title{
Consumption of blueberries with a high-carbohydrate, low-fat breakfast decreases postprandial serum markers of oxidation
}

\author{
Bryan C. Blacker ${ }^{1}$, Shannon M. Snyder ${ }^{1}$, Dennis L. Eggett ${ }^{2}$ and Tory L. Parker ${ }^{1 *}$ \\ ${ }^{1}$ Department of Nutrition, Dietetics, and Food Science, Brigham Young University, S-243 ESC, Provo, UT 84602, USA \\ ${ }^{2}$ Department of Statistics, Brigham Young University, 223 TMCB, Provo, UT 84602, USA
}

(Submitted 10 April 2012 - Final revision received 11 July 2012 - Accepted 18 July 2012 - First published online 31 August 2012)

\begin{abstract}
We sought to determine whether consumption of blueberries could reduce postprandial oxidation when consumed with a typical highcarbohydrate, low-fat breakfast. Participants ( $n$ 14) received each of the three treatments over 3 weeks in a cross-over design. Treatments consisted of a high blueberry dose $(75 \mathrm{~g})$, a low blueberry dose $(35 \mathrm{~g})$ and a control (ascorbic acid and sugar content matching that of the high blueberry dose). Serum oxygen radical absorbance capacity (ORAC), serum lipoprotein oxidation (LO) and serum ascorbate, urate and glucose were measured at fasting, and at 1,2 and $3 \mathrm{~h}$ after sample consumption. The mean serum ORAC was significantly higher in the $75 \mathrm{~g}$ group than in the control group during the first $2 \mathrm{~h}$ postprandially, while serum LO lag time showed a significant trend over the $3 \mathrm{~h}$ for both blueberry doses. Changes in serum ascorbate, urate and glucose were not significantly different among the groups. To our knowledge, this is the first report that has demonstrated that increased serum antioxidant capacity is not attributable to the fructose or ascorbate content of blueberries. In summary, a practically consumable quantity of blueberries ( $75 \mathrm{~g}$ ) can provide statistically significant oxidative protection in vivo after a high-carbohydrate, low-fat breakfast. Though not tested directly, it is likely that the effects are due to phenolic compounds, either directly or indirectly, as they are a major family of compounds in blueberries with potential bioactive activity.
\end{abstract}

Key words: Blueberries: Postprandial oxidation: Oxygen radical absorbance capacity: Serum lipoprotein oxidation

Epidemiological and clinical evidence suggests that berry intake is associated with a reduced risk for $\mathrm{CVD}^{(1,2)}$. An early theory proposed that the protective effect may occur one meal at a time ${ }^{(3)}$. Blood sugar and insulin are high during approximately the first $2 \mathrm{~h}$ after a meal. Free radical production increases during the postprandial period due to normal metabolism after consuming carbohydrate and fat ${ }^{(4)}$. The postprandial period is when free radicals damage arterial epithelial cells and oxidise lipoproteins, leading to cell damage, white cell recruitment, foam cell formation, thickening of the arterial lining and the accumulation of atherosclerotic plaques with the cumulative result of CVD. Protecting against this postprandial oxidation may thus be protective against the development of CVD.

Blueberries are an excellent source of phenolic compounds, including many anthocyanidin glycosides, quercetin and other related compound glycosides, and chlorogenic acid ${ }^{(5,6)}$. These compounds may contribute to the cardiovascular, cancer cell inhibition and blood sugar-moderating benefits of berries ${ }^{(7)}$. Blueberries have a total phenolic content of about $412 \mathrm{mg}$ gallic acid equivalents $100 \mathrm{~g}$ fresh weight ${ }^{(5)}$. Phenolic compounds have an antioxidant capacity significantly higher than vitamin $\mathrm{C}$ or $\mathrm{E}^{(8)}$. However, it is unclear to what extent in vitro antioxidant capacities might translate into in vivo postprandial protection ${ }^{(9)}$. Some evidence suggests that, if consumed with macronutrients, berries may inhibit oxidation during the postprandial period ${ }^{(10-12)}$. More work is needed to understand the in vivo antioxidative effects of berries when consumed with common foods and portion sizes.

One measure of total antioxidant capacity, oxygen radical absorbance capacity (ORAC), shows that fresh blueberries contain $4600 \mu \mathrm{mol}$ Trolox equivalents/100 g fresh weight ${ }^{(13)}$. Blueberries have higher ORAC values than cherries, strawberries, oranges or bananas. Despite the high antioxidant capacity and apparent health benefits of blueberries ${ }^{(1)}$, fruit phenolic compounds have been found to be poorly bioavailable (the percentage that gets absorbed $)^{(14)}$. This suggests a potential disconnect between laboratory values and human health. More in vivo work is necessary to support in vitro measures of fruit, including blueberries.

The main study objective was to determine whether dietary manipulation of blueberries would have a significant impact

Abbreviations: BSTFA w/1\% TMCS, N,O-bis(trimethylsilyl) trifluoroacetamide with 1\% trimethylchlorosilane; LO, lipoprotein oxidation; ORAC, oxygen radical absorbance capacity.

*Corresponding author: T. L. Parker, fax +1 801422 0258, email tory_parker@byu.edu 
on measures of postprandial serum oxidation when controlling for sugar (fructose can increase serum urate, which provided the significant antioxidant effect after apple consumption in Lotito \& Frei $^{(15)}$ ) and ascorbic acid (provided the significant antioxidant protection after strawberry consumption in Tulipani et al. $\left.{ }^{(16)}\right)$. The second objective was to determine the extent to which two quantities of blueberries contributed to antioxidation compared with a control treatment (sugar and ascorbic acid as found in $75 \mathrm{~g}$ blueberries). A final objective of the present study was to answer whether such a quantity of blueberries consumed would provide consumers with detectable short-term antioxidant benefits following a high-carbohydrate, low-fat breakfast. It was hypothesised that a high $(75 \mathrm{~g}$ or $1 / 2$ cup) but consumable quantity of blueberries would significantly decrease serum oxidation postprandially, that it would be significantly more effective than a smaller dose $(35 \mathrm{~g})$ and that both doses would be significantly better than the control.

\section{Materials and methods}

\section{Materials}

2,2'-Azobis (2-amidino-propane) dihydrochloride was purchased from Wako Chemicals. Common buffer ingredients, fluorescein, perchloric acid, Trolox and methanol were purchased from Fisher Scientific. Dithiothreitol, $m$-phosphoric acid and cupric sulphate pentahydrate were purchased from Sigma Chemical. Dimethylformamide (silylation grade) and $\mathrm{N}, \mathrm{O}$-bis(trimethylsilyl) trifluoroacetamide with $1 \%$ trimethylchlorosilane (BSTFA w/1\% TMCS) were purchased from Pierce. Kellogg's Corn Flakes ${ }^{\circledR}$ (brand was chosen for ease of reproducibility) and $2 \%$ milk were bought each week from a local supermarket. Freeze-dried blueberry powder was provided by the US Highbush Blueberry Council (Tifblue/Rubel (Vaccinium virgatum/Vaccinium corymbosum) cultivars, 50/50 blend, approximately 6:1 ratio of fresh:dried).

\section{Collection of serum samples}

Blood was drawn into sterile serum Vacuette tubes $(9 \mathrm{ml}$; Fisher Scientific) by a trained phlebotomist. Serum blood samples were allowed to clot in the dark (room temperature, $30 \mathrm{~min}$ ), centrifuged ( $1500 \mathrm{~g}, 10 \mathrm{~min})$, aliquoted, $\mathrm{N}_{2}$ flushed and stored at $-80^{\circ} \mathrm{C}$.

\section{Subjects}

Fig. 1 shows an overview of the experimental design. A total of fifteen healthy (average BMI 23.6 (range $20.0-28 \cdot 0$ ) kg/ $\mathrm{m}^{2}$; no history of major disease), non-smoking subjects between the ages of 18 and 27 years (average age 22.2 years) were recruited. The fifteen participants were randomly divided into three groups of five people. A brief health questionnaire, description of the study, liability waiver and right to opt out of the study were provided to each participant, in addition to compensation for the participant's time. The present study was conducted according to the guidelines laid down in the Declaration of Helsinki and all procedures involving human subjects were approved by the Brigham Young University's Institutional Review Board before any recruitment or data collection. Written informed consent was obtained from all subjects. As the objective of the study was to determine the postprandial effects of blueberries under free-living

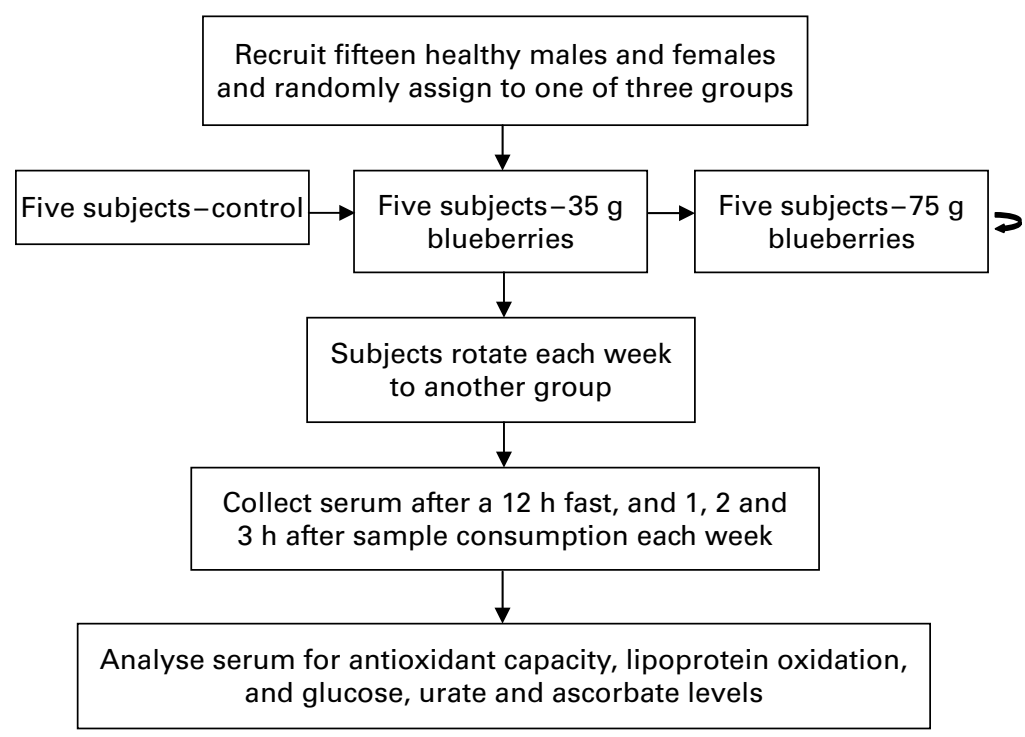

Timeline

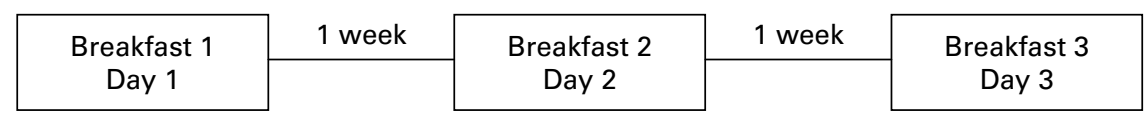

Fig. 1. Experimental design and timeline. 
conditions, no detailed dietary questions were asked. In the review by Manach et al. ${ }^{(14)}$, the longest half-life of postprandial serum phenolic compounds from blueberries was $4 \mathrm{~h}$. The $12 \mathrm{~h}$ fast eliminated any pre-existing serum phenolic compounds from the blood. Subjects were instructed to continue with their usual diet. However, they were asked to discontinue any antioxidant supplements at least 1 week before the beginning of the study period to avoid high doses of antioxidants that could confound results. The study spanned three study days with 1 week between the treatment/blood collection days (see Fig. 1, timeline).

\section{Experimental design}

Following an overnight $12 \mathrm{~h}$ fast, each participant was given $28 \mathrm{~g}$ (one cup) of Kellogg's Corn Flakes ${ }^{\circledR}$ and $118 \mathrm{ml}$ ( $1 / 2$ cup) of $2 \%$ milk to represent a typical high-carbohydrate breakfast. In addition, participants received either (1) control (ascorbic acid ( $1.51 \mathrm{mg}$ ) and sugar (a mixture of fructose $(3.95 \mathrm{~g})$ and glucose (3.76 g) as found in $75 \mathrm{~g}$ of fresh blueberries)), (2) $5.83 \mathrm{~g}$ of freeze-dried blueberry powder ( $35 \mathrm{~g}$ fresh equivalent) or (3) $12.5 \mathrm{~g}$ of freeze-dried blueberry powder ( $75 \mathrm{~g}$ fresh equivalent). To determine how many blueberries a consumer would realistically add to a bowl of corn flakes and milk, a blind pre-trial with four participants was performed. The maximum amount added among the participants was $35 \mathrm{~g}$ of blueberries. This amount was selected as the low-blueberry group. The $75 \mathrm{~g}$ high-blueberry group amount is the weight of a US Department of Agriculture-defined half cup serving.

The control was created to contain the same amounts of glucose $(3.76 \mathrm{~g})$, fructose $(3.95 \mathrm{~g})$ and ascorbic acid $(1.51 \mathrm{mg})$ as found in the $12.5 \mathrm{~g}$ of freeze-dried blueberry powder (according to data provided by the US Highbush Blueberry Council $^{(17)}$ ). The blueberry supplement (per US Highbush Blueberry Council data) had $3.438 \mathrm{~g}$ of total phenolics per $100 \mathrm{~g}, 1.29 \mathrm{~g}$ of which were anthocyanins. The ORAC value for the blueberry powder was $294 \mu \mathrm{mol}$ Trolox equivalents/ g powder (approximately $4900 \mu \mathrm{mol}$ Trolox equivalents/ $100 \mathrm{~g}$ fresh weight). Also contained in $12.5 \mathrm{~g}$ of the blueberry powder but not included in the control was $2.39 \mathrm{~g}$ dietary fibre, $7 \cdot 14 \mu \mathrm{g}$ of total $\beta$-carotene, $55 \cdot 1 \mathrm{mg} \mathrm{K}$ and $3.06 \mathrm{mg} \mathrm{Ca}$. The control mixture was administered to participants by dissolving it in approximately $360 \mathrm{ml}$ of water. The blueberry powder was mixed with water, with rinsing of the container with water until all of the powder had been consumed.

Each group of five participants received one of the three treatment samples every week. Therefore, all participants received all three treatments by the conclusion of the study. Immediately before receiving the breakfast and treatment, a baseline fasting blood sample was collected from each participant. Participants were then given cereal, milk and one of the three treatment samples to consume, and were asked to consume it immediately (within $15 \mathrm{~min}$ ) following their baseline blood sample. Participants provided three additional blood samples at 1, 2 and $3 \mathrm{~h}$ after the first blood sample. Participants were required to remain in the study room over the $3 \mathrm{~h}$ period, except for restroom breaks. Additional water intake was not restricted.
ORAC was measured for an overall picture of serum antioxidant protection, serum lipoprotein oxidation (LO) focused on lipoprotein lipid oxidation protection, and urate, ascorbate and glucose were chosen to measure small molecule changes after a high-carbohydrate, low-fat breakfast with or without blueberries.

\section{Oxygen radical absorbance capacity}

The ORAC $_{\text {PCA }}$ assay $^{(18,19)}$ was performed as a measure of serum antioxidant capacity on a BioTek Synergy 2 plate reader (BioTek Instruments, Inc.) using ninety-six-well black side with clear bottom plates (Corning, Inc.). In brief, one part serum was mixed with one part $0.5 \mathrm{M}$-perchloric acid, vortexed briefly and centrifuged $(15000 \mathrm{~g}, 1 \mathrm{~min})$. The supernatant was removed and diluted 1:18 in $75 \mathrm{~mm}$-phosphate buffer ( $\mathrm{pH} 7$ ), before adding to the wells. Each well contained $120 \mu \mathrm{l}$ of $70.3 \mathrm{~nm}$-fluorescein (prepared in phosphate buffer, final concentration), $20 \mu \mathrm{l}$ of phosphate buffer (blank), Trolox (prepared in phosphate buffer) or sample and $60 \mu \mathrm{l}$ of $12 \mathrm{~mm}-2^{\prime}$-azobis(2-amidinopropane) dihydrochloride (final concentration), added immediately before beginning measurement. Parameters of the assay were as follows: temperature, $37^{\circ} \mathrm{C}$; number of readings, 120 ; time between the readings, $60 \mathrm{~s} ; 3 \mathrm{~s}$ initial shaking and $3 \mathrm{~s}$ of shaking before each reading. For each plate, a Trolox standard curve of 1 , 2,4 and $8 \mu \mathrm{m}$-Trolox (final concentration) was included in triplicate. Each sample was also measured in triplicate. Measurement was made at an emission wavelength of $528 / 20 \mathrm{~nm}$ and an excitation wavelength of $485 / 20 \mathrm{~nm}$. Results were expressed in $\mu \mathrm{mol}$ Trolox equivalents/ 1 of serum.

\section{Serum lipoprotein oxidation}

Cu-induced ( $12 \mu \mathrm{M}$-cupric sulphate, final concentration) serum oxidation $(0.67 \%$ serum diluted in PBS) was performed according to Regnström et al. ${ }^{(20)}$. Oxidation of lipoproteins, as indicated by conjugated diene formation, was measured in the serum without specific isolation of $\mathrm{LDL}^{(21)}$, allowing for analysis of lipoprotein oxidation (LO) in the presence of other components in serum. UV wavelength ninety-six-well flat-bottom plates (Fisher Scientific) were filled with $200 \mu \mathrm{l}$ reaction mixture and the reaction was monitored in the BioTek Synergy 2 plate reader every $5 \mathrm{~min}$ for $4 \mathrm{~h}\left(37^{\circ} \mathrm{C}\right)$ at an absorbance of $234 \mathrm{~nm}$ using Gen 5 software (BioTek Instruments, Inc.). All samples were analysed in triplicate. The BioTek Synergy 2 plate reader was set at $44^{\circ} \mathrm{C}$ to maintain a $37^{\circ} \mathrm{C}$ temperature in the wells. The first four readings were eliminated to allow samples to reach $37^{\circ} \mathrm{C}$. The fifth reading served as a baseline for calculations. The AUC and lag time (intercept between the baseline and the tangent of the absorbance curve during the propagation phase) were calculated using Microsoft Excel.

\section{Ascorbate and urate}

HPLC was performed according to Parker et al. ${ }^{(21)}$ to quantify ascorbate and urate. Briefly, $100 \mu$ l of serum were mixed with 
a $100 \mu \mathrm{l}$ solution of $4.2 \mathrm{~mm}$-dithiothreitol in $0 \cdot 1 \mathrm{M}-\mathrm{K}_{2} \mathrm{HPO}_{4}$ $(\mathrm{pH} 7 \cdot 0$ ). The solution was briefly vortexed and $200 \mu \mathrm{l}$ of $4.5 \% \mathrm{~m}$-phosphoric acid were added. After vortexing, samples were centrifuged for $5.0 \mathrm{~min}(15000 \mathrm{~g})$. The supernatant was transferred to HPLC vials for analysis. All samples were analysed immediately after preparation. Standard curves for ascorbic acid and uric acid were prepared fresh in double-distilled water, and then diluted with dithiothreitol and $m$-phosphoric acid solutions as above.

\section{Glucose}

Glucose analysis of serum was carried out using GC. Serum samples were thawed from $-80^{\circ} \mathrm{C}$ and $1.0 \mathrm{ml}$ of methanol was added to $100 \mu \mathrm{l}$ of serum. Samples were then vortexed and centrifuged for $5.0 \mathrm{~min}(10000 \mathrm{~g})$. The supernatant $(900 \mu \mathrm{l})$ was dried under $\mathrm{N}_{2}$ on a $75^{\circ} \mathrm{C}$ hot plate. Dried samples were reconstituted with $100 \mu \mathrm{l}$ of dimethylformamide followed by $100 \mu \mathrm{l}$ of BSTFA w/1\% TMCS. Reconstituted samples were then vortexed and centrifuged for $2 \mathrm{~min}$ $(15000 \boldsymbol{g})$. The supernatant was transferred to GC vials and heated in an oven at $75^{\circ} \mathrm{C}$ for $15 \mathrm{~min}$ before insertion into the GC system. The initial temperature was $145^{\circ} \mathrm{C}$ for $1 \mathrm{~min}$ ramp to $160^{\circ} \mathrm{C}$ at a rate of $8^{\circ} \mathrm{C} / \mathrm{min}$ and was held for $5 \mathrm{~min}$. The temperature was then ramped to $225^{\circ} \mathrm{C}$ at a rate of $10^{\circ} \mathrm{C} / \mathrm{min}$ and then ramped to $275^{\circ} \mathrm{C}$ at a rate of $10^{\circ} \mathrm{C} / \mathrm{min}$. Inlet and detector temperatures were both $300^{\circ} \mathrm{C}$. Split flow and a flame ionisation detector with an Rtx- 1 column $(30 \mathrm{~m}$ in length, $0.32 \mathrm{~mm}$ in diameter, $0.25 \mu \mathrm{m}$ film) were employed. The injection volume was $3 \mu \mathrm{l}$. Standards were prepared fresh in double-distilled water, and then diluted with methanol, dimethylformamide and BSTFA w/1\% TMCS as above.

\section{Statistical analyses}

Before the study, a power analysis using $\alpha=0 \cdot 05, \beta=0 \cdot 2$ and a meaningful difference of 1 , with a standard deviation of 0.5 (based on the ORAC), determined that four participants per treatment group each week were more than sufficient to obtain statistical significance in a cross-over design. To allow for the possibility of participant attrition, five participants were recruited per group. Significant differences were determined using a mixed-model ANOVA and $P<0.05$ as the cutoff for significance (SAS statistical software, version 9.2; SAS Institute, Inc.). Each subject served as his or her own control. Postprandial values were compared with pretreatment fasting baseline levels, with the mean of the triplicate fasting blood sample for each participant in each assay being subtracted from each replicate obtained at 1,2 and $3 \mathrm{~h}$. The calculated differences were then grouped by treatment. Week, hour, treatment and treatment $x$ hour interaction were factors included in the model. All standard errors reported in figures are those calculated in the treatment $\times$ hour comparison. Tukey's adjusted pairwise comparisons were made for all post hoc tests.

\section{Results}

Data were obtained on average for fourteen participants. If an initial committed participant was unable to participate, an alternate replaced them. Only one participant dropped out after the second visit due to bruising. On occasion, one of the four hourly blood samples was not obtained due to difficulty in locating a vein. If a fasting sample could not be obtained, the participant was dismissed for that day, since the value for the first sample could not then be subtracted from concentrations in subsequent samples for statistical analysis.

\section{Oxygen radical absorbance capacity}

At $1 \mathrm{~h}$ after the fasting blood sample, the high-blueberry group had a significantly larger mean ORAC change than the control $(P=0.03$; Fig. 2 ). At $2 \mathrm{~h}$, the high-blueberry group provided significantly $(P=0.01)$ more antioxidant protection than the low-blueberry and control groups and was also significantly higher than the fasting levels $(P=0.001)$. At $3 \mathrm{~h}$, the pattern was similar, though with overall lower ORAC values, suggesting that the blueberry powder was no longer protective against oxidation. Serum antioxidant capacity was lower than in the fasting blood by $3 \mathrm{~h}$ after a high-carbohydrate, low-fat meal, regardless of the sample group.

\section{Serum lipoprotein oxidation}

There were no significant differences in serum LO AUC change (lower AUC values indicate greater protection from LO) during the first $2 \mathrm{~h}$ postprandially, though at $3 \mathrm{~h}$, it was significantly lower in the control group than in the high-blueberry group ( $P=0 \cdot 03$; Fig. 3 ).

There was no statistically significant difference among the three treatments at any time point for serum LO lag-time change (higher values indicate a longer time to initiation of oxidation; Fig. 4). However, there was significant evidence of a positive trend ( $P$ value for $1 \mathrm{~h} 1 v .2 \mathrm{~h}$ was $0.08,1 \mathrm{~h} v$. $3 \mathrm{~h}$ was 0.009 , and $2 \mathrm{~h} v$. $3 \mathrm{~h}$ was 0.9 for the low-blueberry treatment) towards protection over time.

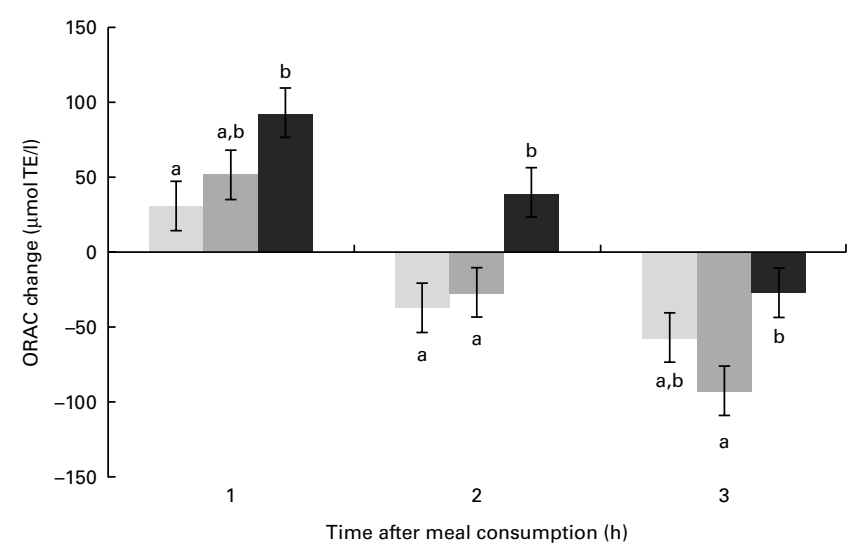

Fig. 2. Oxygen radical absorbance capacity (ORAC) change ( $\mu \mathrm{mol}$ Trolox equivalents $(T E) / l)$ at 1,2 and $3 \mathrm{~h}$ after consuming a control ( $\square$ ), low-blueberry dose $(35 \mathrm{~g}, \square)$ or high-blueberry dose $(75 \mathrm{~g}, \square)$ with a typical breakfast. Fasting blood values were subtracted from each hour for each individual participant before pooling treatment groups. Values are means ( $n 14$ for each treatment within each hour), with standard errors represented by vertical bars. ${ }^{a, b}$ Mean values with unlike letters were significantly different $(P<0.05)$ between the treatments within each hour. 


\section{Urate}

At $1 \mathrm{~h}$ after consuming the provided breakfast and treatment, the high-blueberry group had the largest increase in urate, though this increase was not statistically significant (Fig. 5(A)). This same trend continued at 2 and $3 \mathrm{~h}$, though the only statistically significant difference was between the low- and high-blueberry groups at $3 \mathrm{~h}(P=0 \cdot 03)$. The surprisingly low urate value for the low-blueberry dose at $3 \mathrm{~h}$ prompted an additional statistical analysis (Fig. 5(B)). In this figure, statistical significance was determined within the treatment. The low-blueberry treatment group at $3 \mathrm{~h}$ had a significantly lower serum urate than that at $1 \mathrm{~h}$.

\section{Serum ascorbate}

Although the high-blueberry group had consistently higher levels of ascorbate throughout the postprandial period, the difference was not large enough to reach statistical significance (Fig. 6). However, averaging all $3 \mathrm{~h}$, there is a significant difference between the control or low-blueberry and highblueberry groups (control $v$. low, $P=0.6$; control $v$. high, $P=0.02$; low $v$. high, $P=0.0008)$. The ascorbate levels for both the control and low-blueberry groups were similar and below the fasting levels for all $3 \mathrm{~h}$.

\section{Serum glucose}

No statistical difference was seen among the treatment groups or between time points within a treatment group (data not shown).

\section{Discussion}

The purpose of the present study was not to demonstrate whether or not blueberries had antioxidant properties, or whether high supplemental doses created positive physiological effects. Rather, the purpose was to determine the minimum

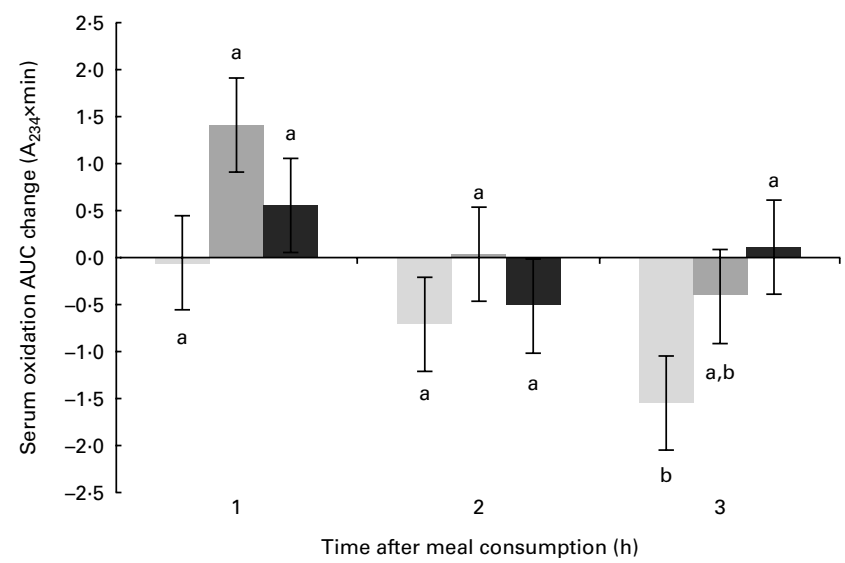

Fig. 3. Changes in lipoprotein oxidation $A \cup C\left(A_{234} \times \min \right)$ at 1,2 and $3 \mathrm{~h}$ after consuming a control $(\square)$, low-blueberry dose $(35 \mathrm{~g}, \square)$ or high-blueberry dose $(75 \mathrm{~g}, \square)$ with a typical breakfast. Lower AUC values indicate greater protection from lipoprotein oxidation. Fasting blood values were subtracted from each hour for each individual participant before pooling treatment groups. Values are means ( $n 14$ for each treatment within each hour), with standard errors represented by vertical bars. ${ }^{\mathrm{a}, \mathrm{b}}$ Mean values with unlike letters were significantly different $(P<0.05)$.

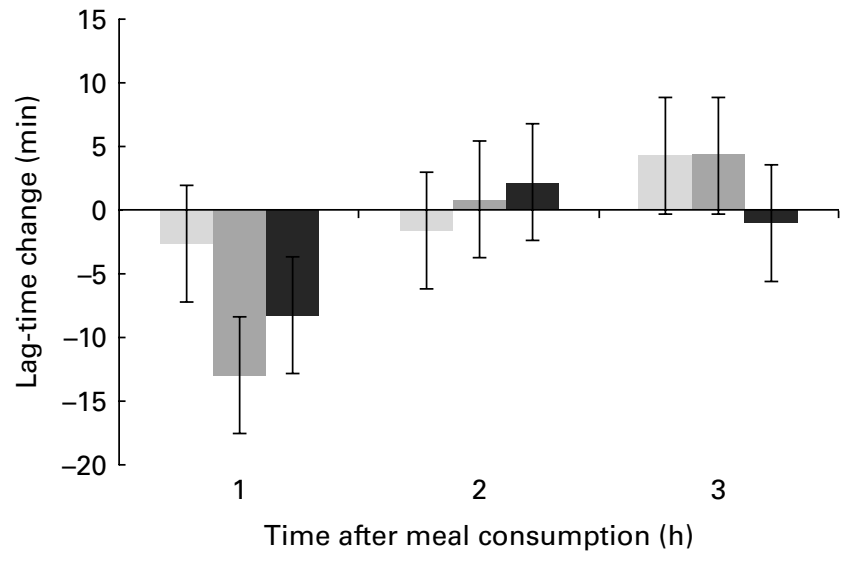

Fig. 4. Lipoprotein oxidation lag-time change (in $\min$ ) at 1,2 and $3 \mathrm{~h}$ after consuming a control $(\square)$, low-blueberry dose $(35 \mathrm{~g}, \square)$ or high-blueberry dose $(75 \mathrm{~g}, \square)$ with a typical breakfast. Higher values indicate greater resistance to the initiation of lipoprotein oxidation. Fasting blood values were subtracted from each hour for each individual participant before pooling treatment groups. Values are means ( $n 14$ for each treatment within each hour), with standard errors represented by vertical bars. There were no statistically significant differences at $P<0.05$. See text for further discussion.

level at which a consumer may realistically expect to receive antioxidant benefits after eating blueberries with a highcarbohydrate, low-fat meal. We report for the first time that blueberries protect against serum oxidation independent of sugar or ascorbic acid content. Previously published blueberry studies have provided participants very large quantities of blueberries $^{(10-12,22)}$. We have demonstrated that a half-cup serving of blueberries is sufficient to inhibit postprandial oxidation.

In this context, two prevailing theories explain how high fruit intake might increase serum antioxidant capacity. Flavonoids are generally poorly absorbed ${ }^{(10,14)}$, which suggests that flavonoids may not directly increase serum antioxidant levels. Lotito \& Frei ${ }^{(15)}$ found that the higher fructose content of fruit causes an increase in serum levels of urate, which has antioxidant activity. This was found to be a more significant contributor to increased serum antioxidant capacity after apple consumption, rather than apple phenolic compounds. A second study ${ }^{(16)}$ suggested that ascorbate was more important than phenolic compounds or urate in increasing postprandial serum antioxidant activity when consuming only strawberries. We have recently found that phenolic compounds directly increase postprandial serum antioxidant capacity $^{(19)}$. In that experiment, both fructose and ascorbate content of navel oranges were included in the control group. By including the same control in the present study, we found a similar effect with blueberries. These results further separate the effects of fructose and ascorbate from the effects of phenolic compounds on measures of human postprandial oxidation.

\section{Blueberry effects on serum antioxidant capacity}

Several recent studies on blueberries examining the effects on postprandial human serum antioxidant capacity have been published. Pedersen et al. ${ }^{(23)}$ found no significant increase 
(A)

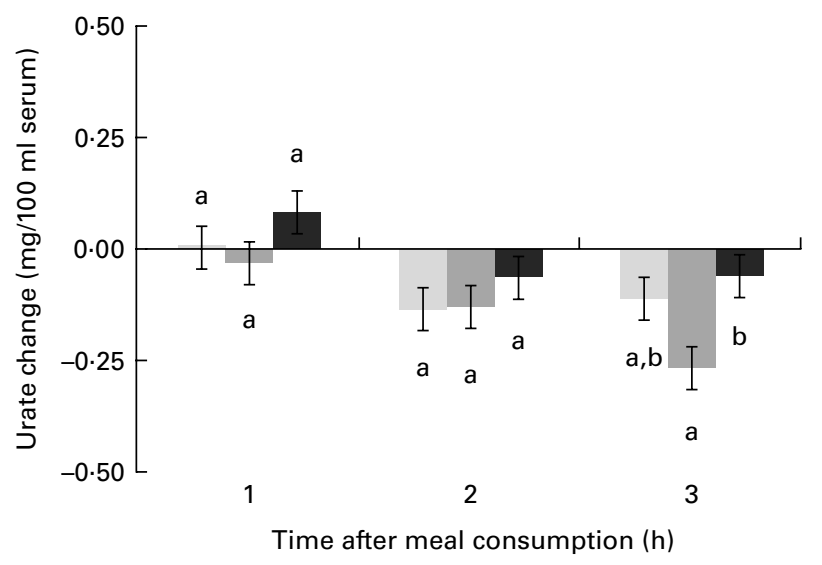

(B)

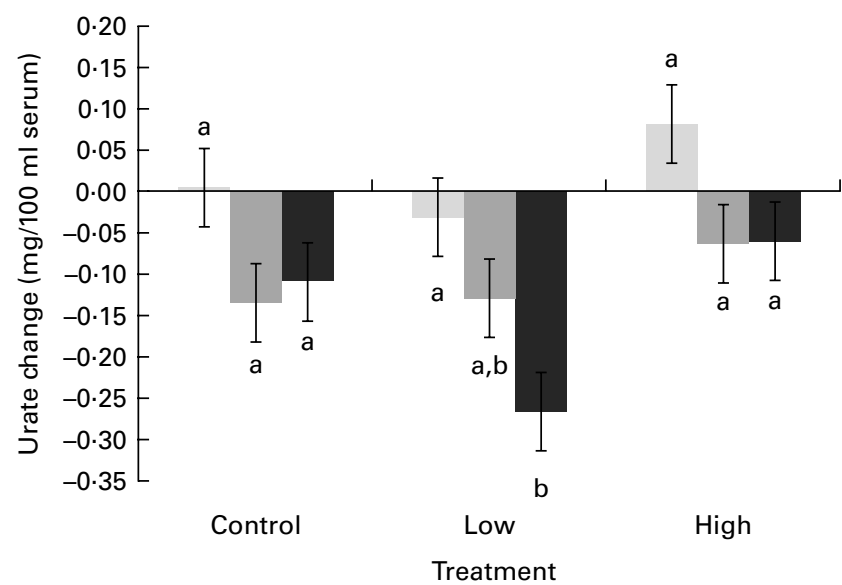

Fig. 5. Change in serum urate (mg serum urate/100 $\mathrm{ml}$ serum) at $1(\square), 2$ $(\square)$ and $3 \mathrm{~h}(\square)$ after consuming a control $(\square)$, low-blueberry dose $(35 \mathrm{~g}, \square)$ or high-blueberry dose $(75 \mathrm{~g}, \square)$ with a typical breakfast. Fasting blood values were subtracted from each hour for each individual participant before pooling treatment groups. Values are means (n 14), with standard errors represented by vertical bars. ${ }^{a, b}$ Mean values with unlike letters were significantly different $(A)$ between the treatments within each hour, or $(B)$ across the hours within a treatment $(P<0.05$ for both).

in plasma antioxidant capacity after females consumed $500 \mathrm{ml}$ of blueberry juice. The study did not replicate free-living conditions, as subjects consumed no additional food or drink with the treatment, so the results are not directly comparable to the present results. Also, the phenolic content of juice was probably significantly lower ${ }^{(24)}$ than that found in the less processed whole powder used in the present study.

Mazza et al. ${ }^{(10)}$ administered $100 \mathrm{~g}$ of freeze-dried blueberry powder (eight times our dose) with a high-fat meal to healthy male subjects. They found a significant increase in serum anthocyanins and antioxidant capacity compared with control subjects. This is in agreement with the present results, though their larger dose resulted in a larger difference between treatment and control than ours. They also did not control for ascorbate or urate. Kay \& Holub ${ }^{(11)}$ published a paper with a design similar to that of Mazza et al. ${ }^{(10)}$. In that paper, $100 \mathrm{~g}$ of freeze-dried blueberry powder were given to healthy human subjects along with a high-fat meal. They separated serum into water- and lipid-soluble fractions. They found a significant increase in serum antioxidant capacity at $1 \mathrm{~h}$ (water-soluble fraction) and $4 \mathrm{~h}$ (lipid-soluble fraction) postconsumption compared with the high-fat meal alone. Though in the present study, subjects consumed a high-carbohydrate, low-fat meal, a significant increase in water-soluble serum antioxidant capacity at $1 \mathrm{~h}$ was also seen with only a $12.5 \mathrm{~g}$ dose of freeze-dried blueberry powder.

Prior et $a l .{ }^{(12)}$ reported a significant increase in serum antioxidant capacity at $1 \mathrm{~h}$ (water-soluble fraction) and $2 \mathrm{~h}$ (lipid-soluble fraction) post-consumption of $189 \mathrm{~g}$ frozen blueberries The dose used in Prior et al. ${ }^{(12)}$ was only 2.5 times our dose, providing support that a smaller dose more likely to be eaten by a consumer can provide a significant increase in serum antioxidant capacity. In contrast to the present study and previously mentioned studies, Prior et al. ${ }^{(12)}$ did not feed subjects anything in addition to the frozen blueberries. Additionally, they also administered a lower dose of blueberries $(94.5 \mathrm{~g}$ ) alone, which did not result in a significant increase in serum antioxidant capacity when compared with their control. Postprandial oxidation of carbohydrate or fat may be important to observe a protective effect of lower doses of blueberry consumption. We report a significant change in antioxidant protection with a dose $(75 \mathrm{~g})$ somewhat lower than the non-significant low dose $(94.5 \mathrm{~g})$ used by Prior et al. ${ }^{(12)}$.

Serafini et al. ${ }^{(25)}$ found that consuming fresh blueberries $(200 \mathrm{~g})$ with milk decreased serum antioxidant capacity and the absorption of phenolic compounds compared with blueberries alone. Since milk was included in all of our treatment groups as part of the administered breakfast, we cannot confirm the results of Serafini et al. ${ }^{(25)}$. However, it is possible that the difference between our control and treatment groups may have been larger were milk not included.

Giongo et al. ${ }^{(26)}$ measured markers of oxidation and inflammation in overweight and obese children over 8 weeks. Though postprandial samples were not collected, it has

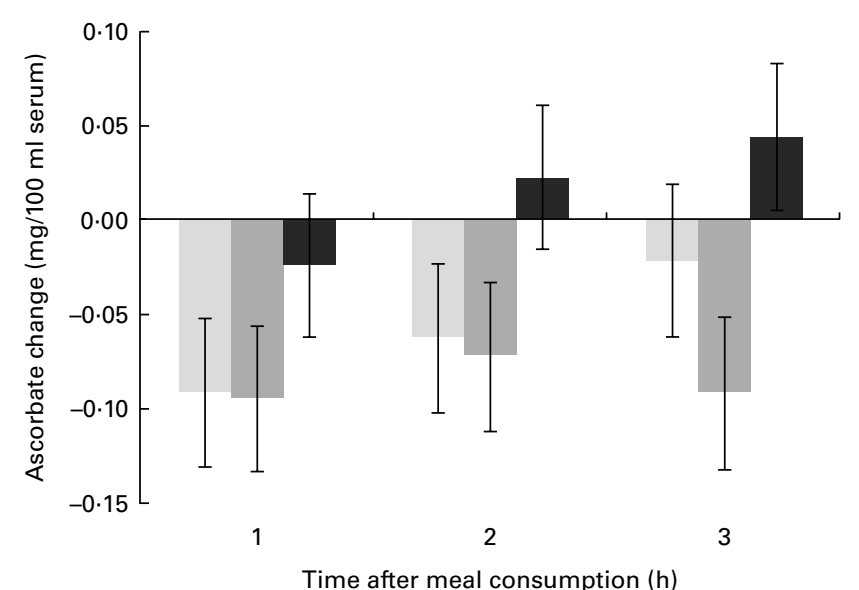

Fig. 6. Changes in serum ascorbate ( $\mathrm{mg}$ ascorbate/100 $\mathrm{ml}$ serum) at 1,2 and $3 \mathrm{~h}$ after consuming a control $(\square)$, low-blueberry dose $(35 \mathrm{~g}, \square)$ or highblueberry dose $(75 \mathrm{~g}, \square)$ with a typical breakfast. Fasting blood values were subtracted from each hour for each individual participant before pooling treatment groups. Values are means ( $n 14$ for each treatment within each hour), with standard errors represented by vertical bars. There were no statistically significant differences at $P<0.05$. See text for further discussion. 
been demonstrated that fresh blueberries decreased oxidative stress and inflammatory markers over a relatively short period of time in an at-risk population.

Of the studies reviewed, only Prior et $a l^{(12)}$ and Serafini et al. ${ }^{(25)}$ used a consumable, though high, quantity of blueberries, though in an artificial condition (blueberries alone or milk and blueberries only). None of the studies controlled for sugar or ascorbate effects. The present study addressed many shortfalls of the foregoing work in a scenario that is likely to occur in a free-living population.

\section{Serum lipoprotein oxidation}

The results in Fig. 3 were the opposite of what was expected. There are three components that contribute to the AUC value: lag time or time until the initiation of oxidation, rate of propagation (slope of the propagation phase) and maximum lipids oxidised. A lower AUC would indicate longer time to initiation, lower propagation slope and/or lower maximum oxidation. However, one factor could outweigh the others, giving an artificial positive. Although one significant value was found in hour 3 , its magnitude of only 1.5 area units suggests that the treatments given did not result in any practically relevant changes in LO AUC. The result may also be reflective of the relatively low blueberry doses, or that blueberry phenolic compounds have a slight negative effect on lipoproteins. Further work is needed at a wider range of blueberry doses to explain this result. No blueberry studies could be found in which LO was measured.

The positive lag-time trend in Fig. 4 may reflect the $4 \mathrm{~h} T_{\max }$ in plasma for blueberry phytochemicals ${ }^{(10)}$. As these molecules increased in serum, they could slow the initiation of LO. This is an encouraging result for a practical dietary dose of blueberries in conjunction with a high-carbohydrate, lowfat breakfast.

\section{Serum urate, ascorbate and glucose}

Since urate has been shown to increase with fructose consumption $^{(15)}$, and the blueberry dose plus breakfast did not provide large amounts of fructose, we did not expect to see a significant increase in serum urate (Fig. 5). In the work of Godycki-Cwirko et $a l{ }^{(27)}$, a study confirming the results of Lotito \& Frei ${ }^{(15)}$, fructose consumption averaged $89.1 \mathrm{~g}$, while in the experiments of Tulipani et $a l^{(16)}$, average intake by participants was $63.9 \mathrm{~g}$ fructose. Heuckenkamp \& Zollner ${ }^{(28)}$ found that intravenous administration of fructose $>0.5 \mathrm{~g}$ fructose $/ \mathrm{kg}$ body weight per $\mathrm{h}$ would induce hyperuricaemia. The average participant body weight in the present study was $71.3 \mathrm{~kg}$, so more than $35 \mathrm{~g}$ of fructose $/ \mathrm{h}$ would need to have been administered to produce similar increases in serum urate levels in our subjects. The present study participants consumed a maximum of $3.95 \mathrm{~g}$ fructose. This low dose may account for why no significant changes were seen in serum urate resulting from fructose intake.

Fig. 6 suggests that the control and low blueberry treatments were not sufficient to maintain fasting serum ascorbate after consumption of the high-carbohydrate, low-fat breakfast.
Halliwell et $a l^{(29)}$ proposed that the gastrointestinal tract may be a major site of action for fruit phenolic compounds. One possible mechanism is that fruit phenolic compounds may keep other antioxidants, such as ascorbic acid, reduced, allowing them to be more active once absorbed. This could explain the higher serum ascorbate with higher blueberry intake in Fig. 6, possibly due to more blueberries providing more bioavailable ascorbate.

Similar to the low amount of fructose found in blueberries, the present study participants in the high-blueberry group received only $1.51 \mathrm{mg}$ ascorbate. Even with an adjustment for fruit weight to match that given to the participants in Tulipani et $a l .{ }^{(16)}$ (1 kg fresh strawberries), participants in the present study consuming blueberries would have only received $2 \cdot 01 \mathrm{mg}$ ascorbate, when compared with $40 \cdot 1 \mathrm{mg}$ ascorbate in the Tulipani et al. ${ }^{(16)}$ study.

Since all groups received the same breakfast and the blueberry sugar amount was small relative to the corn flakes consumed, we did not expect to see a significant change in serum glucose. It was important to measure, however, as Manzano \& Williamson ${ }^{(30)}$ found that flavonoid compounds may delay the absorption of glucose. If any delay occurred, it was probably not detectable due to the efficiency of carbohydrate absorption and the hour delay between blood samples.

There were no significant changes in serum glucose either within the treatment groups or between the time points comparing a single treatment group. A mechanism that may possibly explain this was recently suggested by Manzano \& Williamson ${ }^{(30)}$. They found that phenolic compounds from strawberries and apples decreased glucose uptake in Caco-2 human intestinal cells. The phenolic compounds bind glucose receptors, slowing the uptake of glucose. A slower flow of glucose into the bloodstream may minimise oxidative stress. To determine whether this effect was seen in the present study, serum glucose was measured. This mechanism, coupled with the relatively minor differences in glucose content among the control, low-blueberry group and high-blueberry groups, may account for the lack of significant change in serum glucose.

One limitation of the present study was that our participant numbers were relatively small. A larger study might allow some of the trends we observed to reach significance. The blueberry powder, while similar to fresh blueberries, may not give the same result as fresh or frozen berries or blueberry juice. Different forms of blueberries were not evaluated in the present study. Because milk was given to all groups, we were unable to determine whether the milk had a negative effect on phenolic compound activity, as was observed by Serafini et al. ${ }^{(25)}$.

In summary, a practically consumable quantity of blueberries $(75 \mathrm{~g})$ can provide statistically significant oxidative protection in vivo after a high-carbohydrate, low-fat breakfast. Serum LO demonstrated a positive trend among both blueberry groups. Averaging across times, we see significant differences in serum ascorbate across the treatments. There appears to be a modest benefit to consuming reasonable amounts of fruit with typical servings of cereal and milk, based on the results obtained, though more work is needed with larger participant 
numbers to determine whether the trends we observed would reach significance. To our knowledge, this is the first report that has demonstrated that increased serum antioxidant capacity is not attributable to the fructose or ascorbate content of blueberries. Though not tested directly, it is likely that the effects are due to phenolic compounds, either directly or indirectly, as they are a major family of compounds in blueberries with potential bioactive activity.

\section{Acknowledgements}

Blueberry powder was provided by the US Highbush Blueberry Council. The authors would like to thank Kevin Lowder for his assistance in processing the collected serum. This study was supported by the Department of Nutrition, Dietetics and Food Science at Brigham Young University. B. C. B. and T. L. P. designed and carried out the study. B. C. B., S. M. S. and T. L. P. performed the laboratory data collection. D. L. E. and T. L. P. performed the statistical data analysis. B. C. B. and T. L. P. wrote the manuscript. The authors declare that there are no conflicts of interest.

\section{References}

1. Basu A, Rhone M \& Lyons TJ (2010) Berries: emerging impact on cardiovascular health. Nutr Rev 68, 168-177.

2. Verlangieri AJ, Kapeghian JC, El-Dean S, et al. (1985) Fruit and vegetable consumption and cardiovascular mortality. Med Hyp 16, 7-15.

3. Zilversmit DB (1979) Atherogenesis: a postprandial phenomenon. Circulation 60, 473-485.

4. Sies H, Stahl W \& Sevanian A (2005) Nutritional, dietary and postprandial oxidative stress. J Nutr 135, 969-972.

5. Zheng W \& Wang SY (2003) Oxygen radical absorbing capacity of phenolics in blueberries, cranberries, chokeberries, and lingonberries. J Agric Food Chem 51, 502-209.

6. US Department of Agriculture \& Agricultural Research Service (2007) USDA Database for the Flavonoid Content of Selected Foods, Release 2.1. Beltsville, MD: US Department of Agriculture, Agricultural Research Service. http://www. ars.usda.gov/Services/docs.htm?docid $=6231$ (accessed January 2012).

7. Battino M, Beekwilder J, Denoyes-Rothan B, et al. (2009) Bioactive compounds in berries relevant to human health. Nutr Rev 67, S145-S150.

8. Tabart J, Kevers C, Pincemail J, et al. (2009) Comparative antioxidant capacities of phenolic compounds measured by various tests. Food Chem 113, 1226-1233.

9. Fernandez-Panchon MS, Villano D, Troncoso A, et al. (2008) Antioxidant activity of phenolic compounds: from in vitro results to in vivo evidence. Crit Rev Food Sci Nutr 48, 649-671.

10. Mazza G, Kay CD, Cottrell T, et al. (2002) Absorption of anthocyanins from blueberries and serum antioxidant status in human subjects. J Agric Food Chem 50, 7731-7737.

11. Kay CD \& Holub BJ (2002) The effect of wild blueberry (Vaccinium angustifolium) consumption on postprandial serum antioxidant status in human subjects. Br J Nutr $\mathbf{8 8}$, 389-397.

12. Prior RL, Go LW, Wu XL, et al. (2007) Plasma antioxidant capacity changes following a meal as a measure of the ability of a food to alter in vivo antioxidant status. $\mathrm{J} \mathrm{Am} \mathrm{Coll} \mathrm{Nutr}$ 26, 170-181.
13. US Department of Agriculture \& Agricultural Research Service (2010) USDA Database for the Oxygen Radical Absorbance Capacity (ORAC) of Selected Foods, Release 2. Beltsville, MD: US Department of Agriculture, Agricultural Research Service. http://www.ars.usda.gov/Services/docs. htm?docid=15866 (accessed January 2012).

14. Manach C, Williamson G, Morand C, et al. (2005) Bioavailability and bioefficacy of polyphenols in humans. I. Review of 97 bioavailability studies. Am J Clin Nutr 81, Suppl. 1, 230S-242S.

15. Lotito SB \& Frei B (2004) The increase in human plasma antioxidant capacity after apple consumption is due to the metabolic effect of fructose on urate, not apple-derived antioxidant flavonoids. Free Radic Biol Med 37, 251-258.

16. Tulipani S, Romandini S, Busco F, et al. (2009) Ascorbate, not urate, modulates the plasma antioxidant capacity after strawberry intake. Food Chem 117, 181-188.

17. US Highbush Blueberry Council (2010) Freeze-Dried Blueberry Powder-20909 Tifblue/Rubel 50/50 Blend. 80 Iron Point Circle, Suite 114, Folsom, CA 95639, USA.

18. Davalos A, Gomez-Cordoves C \& Bartolome B (2004) Extending applicability of the oxygen radical absorbance capacity (ORAC-fluorescein) assay. J Agric Food Chem 52, 48-54.

19. Snyder SM, Reber JD, Freeman BL, et al. (2011) Controlling for sugar and ascorbic acid, a mixture of flavonoids matching navel oranges significantly increases human postprandial serum antioxidant capacity. Nutr Res 31, 519-526.

20. Regnström J, Strom K, Moldeus P, et al. (1993) Analysis of lipoprotein diene formation in human serum exposed to copper. Free Radic Res Commun 19, 267-278.

21. Parker TL, Wang XH, Pazmiño J, et al. (2007) Antioxidant capacity and phenolic content of grapes, sun-dried raisins, and golden raisins and their effect on ex vivo serum antioxidant capacity. J Agric Food Chem 55, 8472-8477.

22. Krikorian R, Shidler MD, Nash TA, et al. (2010) Blueberry supplementation improves memory in older adults. J Agric Food Chem 58, 3996-4000.

23. Pedersen CB, Kyle J, Jenkinson AMcE, et al. (2000) Effects of blueberry and cranberry juice consumption on the plasma antioxidant capacity of healthy female volunteers. Eur $J$ Clin Nutr 54, 405-408.

24. Kalt W, McDonald JE \& Donner H (2000) Anthocyanins, phenolics and antioxidant capacity of processed lowbush blueberry products. J Food Sci 65, 390-393.

25. Serafini M, Testa MF, Villaño D, et al. (2009) Antioxidant activity of blueberry fruit is impaired by association with milk. Free Radic Biol Med 46, 769-774.

26. Giongo L, Bozza E, Caciagli P, et al. (2011) Short-term blueberry intake enhances biological antioxidant potential and modulates inflammation markers in overweight and obese children. J Berry Res 1, 147-158.

27. Godycki-Cwirko M, Krol M, Krol B, et al. (2010) Uric acid, but not apple polyphenols is responsible for the rise of plasma antioxidant activity after apple juice consumption in healthy subjects. J Am Coll Nutr 29, 397-406.

28. Heuckenkamp PU \& Zollner N (1971) Fructose-induced hyperuricaemia. Lancet i, 808-809.

29. Halliwell B, Zhao K \& Whiteman M (2000) The gastrointestinal tract: a major site of antioxidant action? Free Radic Res 33, 819-830.

30. Manzano S \& Williamson G (2010) Polyphenols and phenolic acids from strawberry and apple decrease glucose uptake and transport by human intestinal Caco-2 cells. Mol Nutr Food Res 54, 1773-1780. 